\title{
РОЛЬ ВУЗОВ-ИНТЕГРАТОРОВ В ЭКОНОМИЧЕСКИ ОБУСЛОВЛЕННОЙ МОДЕЛИ ВЫСШЕГО УЧЕБНОГО ЗАВЕДЕНИЯ
}

\author{
(c) 2020 Николаева Елена Анатольевна \\ кандидат социологических наук, доцент, кафедра иностранных языков № 3 \\ Российский экономический университет им. Г. В. Плеханова, Россия, Москва \\ E-mail: yoltash82@mail.ru
}

\section{(C) 2020 Кузнецова Юлия Андреевна}

кандидат экономических наук, доцент, кафедра иностранных языков № 3 Российский экономический университет им. Г. В. Плеханова, Россия, Москва E-mail:yulia_success@mail.ru

\section{(c) 2020 Копылова Елена Викторовна}

кандидат филологических наук, доцент, кафедра иностранных языков № 3 Российский экономический университет им. Г. В. Плеханова, Россия, Москва

E-mail: Kopylova.EV@rea.ru

\section{(c) 2020 Панченко Екатерина Юрьевна}

старший преподаватель, кафедра иностранных языков № 3

Российский экономический университет им. Г. В. Плеханова, Россия, Москва

E-mail: katya368@yandex.ru

В статье авторов анализируется роль вузов-интеграторов в экономически обусловленной модели высшего учебного заведения. Объектом исследования выступили вузы-интеграторы, а предметом - экономически-обусловленная модель высшего учебного заведения. Теоретическое и методологическое значение исследования заключены в развитии теории и методологии функциональной нагрузки высших учебных заведений в аспекте их интеграционного пространства. Практическое значение исследования заключено в уточнении значимых причин сокращения количества высших учебных заведений параметров и группировке высших учебных заведений Российской Федерации по их экономическому положению.

Ключевые слова: Роль, высшее учебное заведение, интегратор, экономика, обусловленность, модель, эффективность, проблема, перспектива.

Кризисные явления в любой сфере человеческой жизни (включая и экономику) всегда определялись такими группами характеристик, как причины и следствия. Согласно устоявшейся этимологической концепции первая из обозначенных групп характеристик определяет сущность и первобытность того или иного явления, а вторая уровень и характер его влияния на параметры внешней и внутренней среды относительно выбранной совокупности объектов и субъектов в определенный период времени [3, 4]. На практике, зачастую, обе из указанных групп характеристик обладают равноценной значимостью, ввиду чего для достижения наилучшего эффекта рассматриваются исследователями совместно.

В теории современной науки институт интеграции применяется достаточно широко, что обуславливает его первостепенную роль в изу- чении любого сложного процесса, объекта или явления.

Не является исключением и экономическая наука, приложенная к множеству актуальных объектов, таких, например, как высшие учебные заведения.

Говоря о высших учебных заведениях в Российской Федерации следует отметить, что в 2020 году они обращают на себя пристальное внимание широкого круга перспективных ученых [1, 2, 3, 4, 5 и других], которых, в частности, довольно часто интересует аспект их интеграции. Так на начало 2020 года популярность термина «интеграция» в отношении термина «высшее учебное заведение» в основных поисковых системах, распространённых на территории Российской Федерации (Yandex, Goggle, Yahoo, Mail, Rambler и другие) поднялась в среднем до 39 процентов против 27 процентов в начале 2019 года и 21 
процента в начале 2018 года [6, 7]. При этом первичность обращения к термину «интеграция» составила у пользователей Российской Федерации на обозначенные даты в среднем 89, 75 и 67 процентов соответственно.

Чуть менее чем двукратный прирост анализируемого показателя за двухлетний период по трем контрольным точкам, на наш взгляд, может явно свидетельствовать о значимой взаимной популяризации обозначенных выше терминов.

Дальнейший анализ обозначенного вопроса позволил прийти к выводу, что среди совокупности высших ученых заведений [1, с. 145] функционирующих на территории Российской Федерации в 2020 году можно четко выделить интеграторов, то есть экономических субъектов, способствующих целевому объединению интересов, функций, подразделений или даже отдельных игроков рынка в более сложные формации на принципах эффективности и взаимовыгодности.

Появление и развитие обозначенных субъектов в Российской Федерации, на наш взгляд, может быть связано как с возникшими здесь кризисными явлениями, так и направлением общей экономической политики в целом. Так по данным ряда источников количество высших учебных заведений в Российской Федерации (как самостоятельных юридических лиц) в целях повышения эффективности высшего образования [2, с. 1495] к 2023 году должно быть сокращено не менее чем в 1,5 раза. Оптимальный же коэффициент сокращения высших учебных заведений по прогнозам экспертов к обозначенному периоду времени должен составить порядка 1,65 раза [6].

Основными значимыми причиной необходимости сокращения количества высших учебных заведений в Российской Федерации, на наш взгляд, являются (по степени убывания среднего уровня значимости по состоянию на начало 2020 года в процентах):

- недостаточная экономическая целесообразность функционирования отдельных экономических субъектов (средний уровень значимости причины составляет порядка 29,86 процентов);

- значительное устаревание основных средств в части движимого и недвижимого имущества (средний уровень значимости причины составляет порядка 23,71 процента);

- низкая кадрово-организационная эффективность функционирования отдельных экономических субъектов (средний уровень значимости причины составляет порядка 18,93 процентов);

- низкая публикационная активность функционирования отдельных экономических субъектов (средний уровень значимости причины составляет порядка 11,16 процентов);

- низкая инновационная активность функционирования отдельных экономических субъектов (средний уровень значимости причины составляет порядка 9,85 процентов);

- прочие причины (средний уровень значимости причины составляет порядка 6,49 процентов).

Исходя из того, что во главе перечня уверенно лидирует причина (отрыв от наименее значимой, за исключением прочих причин, причины составляет более 3 раз), связанная с недостаточной экономической целесообразностью функционирования высших учебных заведений в Российской Федерации, рассмотрим ее более подробно.

Согласно экономически-обусловленной модели высшего учебного заведения [5, с. 56] его текущая активность в настоящем, а также в среднесрочной и долгосрочной перспективах функционирования должна быть экономически целесообразна. Это означает, что деятельность заведения, не отвечающего данному требованию в течение длительного периода времени должна быть скорректирована, а в дальнейшем при не достижении положительных результатов либо полностью приостановлена, либо передана под контроль более эффективному субъекту рынка.

Информация по группировке экономического положения высших учебных заведений в Российской Федерации по состоянию на начало 2020 года приведена ниже в перечне (в скобках указана доля высших учебных заведений, принадлежащих к той или иной группе):

- высшее учебное заведение не испытывает каких-либо значимых трудностей экономического характера (на данную группу приходилось порядка 5,83 процента высших учебных заведений);

- высшее учебное заведение испытывает некоторые не существенные трудности экономического характера (на данную группу приходилось порядка 15,75 процента высших учебных заведений);

- высшее учебное заведение испытывает существенные трудности экономического ха- 
рактера (на данную группу приходилось порядка 29,81 процента высших учебных заведений);

- экономическое положение высшего учебного заведения можно оценить как кризисное (на данную группу приходилось порядка 35,54 процента высших учебных заведений);

- высшее учебное заведение находится в той или иной стадии экономической реструктуризации (на данную группу приходилось порядка 13,07 процента высших учебных заведений).

Из перечня видно, что на обозначенную дату более половины высших учебных заведений в Российской Федерации испытывали трудности экономического характера. Исходя из чего, в ближайшее время они могут быть в той или иной мере интегрированы с более эффективными высшими учебными заведениями в обозначенной географической формации.

Исходя из этого в целях данной публикации была выяснена роль вузов-интеграторов в экономически обусловленной модели высшего учебного заведения.

Основываясь на том, что роль любой экономической категории проявляется через ее функции, ниже нами были систематизированы функции высших учебных заведений, выступающие в качестве интеграторов (в скобках приведена значимость каждой функции от 0 до 100 баллов соответственно):

- реструктуризация и поглощение экономически не эффективных учреждений на рынке образования Российской Федерации (значимость функции оценивается в 35 единиц из 100 возможных);

- формирование центров распределения и перераспределения информационных потоков высших учебных заведений (значимость функции оценивается в 20 единиц из 100 возможных);

- организация и проведение межвузовских научных конференций (значимость функции оценивается в 5 единиц из 100 возможных);

- организация и проведение межвузовских исследований в различных (в том числе смежных) областях (значимость функции оценивается в 5 единиц из 100 возможных);

- формирование и дальнейшая эксплуатация единой методической и методологической базы знаний (значимость функции оценивается в 10 единиц из 100 возможных);

- формирование центра (центров) по подготовке (переподготовке) профессорско- преподавательского состава (значимость функции оценивается в 15 единиц из 100 возможных);

- прочие возможные функции (значимость функции оценивается в 10 единиц из 100 возможных).

Таким образом, можно сделать вывод, что термины «высшее учебное заведение» и «интеграция» достаточно тесно расположены в глобальной индексной таблице, составленной по данным основных поисковых систем. При этом популярность данного словосочетания за последние два года поднялась в среднем в 1,86 раза с существенным превалированием последнего из них.

Под вузом-интегратором понимается экономический субъект, способствующий целевому объединению интересов, функций, подразделений или даже отдельных игроков рынка в более сложные формации на принципах эффективности и взаимовыгодности.

Согласно предварительным прогнозам, полученным экспертами, общее количество высших учебных заведений на рынке Российской Федерации, подвергнутых процедурам интеграции посредствам объединения с более эффективными субъектами, значительно увеличится, а совокупное количество высших учебных заведений (как самостоятельных юридических лиц) уменьшится в 1,65 раза.

Обозначенные прогнозные данные в значительной степени подтверждаются информацией по текущему экономическому положению высших учебных заведений в Российской Федерации.

Роль вуза-интегратора в экономически обусловленной модели высшего учебного заведения заключается в выполнении следующих функций: реструктуризация и поглощение экономически не эффективных учреждений на рынке образования Российской Федерации; формирование центров распределения и перераспределения информационных потоков высших учебных заведений; организация и проведение межвузовских научных конференций; организация и проведение межвузовских исследований в различных (в том числе смежных) областях; формирование и дальнейшая эксплуатация единой методической и методологической базы знаний; формирование центра (центров) по подготовке (переподготовке) профессорскопреподавательского состава и прочее. 


\section{Библиографический список}

1. Закалин И. Ю., Ерохин В.В. Методика оценки социально-экономического состояния образовательного учреждения (вуза) / И.Ю.Закалин, В.В.Ерохин // Вестник современных исследований - Омск: Изд-во: «ИП Соловьев В. А.», 2019. - № 28.- С. 143-150.

2. Мельников Р. М. Оценка внешних эффектов распространения высшего образования в российских условиях / Р.М. Мельников // Экономический анализ: теория и практика - Москва: Изд-во: «ООО «Издательский дом ФИНАНСЫ И КРЕДИТ», 2020. - № 8.- С. 1490-1511.

3. Николаева Е. А., Казимирова И. С., Панченко Е. Ю., Родникова О. Ю. К вопросу оценки эффективности финансирования высших учебных заведений на основе анализа рейтинга профессорско-преподавательского состава / Е.А. Николаева, И. С. Казимирова, Е. Ю.Панченко, О. Ю. Родникова // Экономические науки - Москва: Изд-во: «ООО «24 Принт», 2019.- № 10.- С. 86-90.

4. Слепов В. А., Роденкова Т. А., Гришина О.А., Минхазетдинова К. З. Парадигма управления финансами вузов России в современных условиях / В.А.Слепов, Т.А.Роденкова, О.А. Гришина, К. З. Минхазетдинова // Финансовая жизнь - М: Изд-во: «Академия менеджмента и бизнес-администрирования», 2020.- № 2.- С. 49-53.

5. Сыготина М. В., Патрусова А.М.Планирование деятельности вуза на основе показателей эффективности, с применением элементов проектного менеджмента / М.В.Сыготина, А.М.Патрусова // Проблемы социально-экономического развития Сибири - Братск: Изд-во ООО «Братский государственный университет», 2019.- № 4.- С. 54-58.

6. Компания «АКРА» [Электронный ресурс]: аналитические материалы - Официальный сайт компании «АКРА», 2020.- Режим доступа: www.acra-ratings.ru/

7. Компания «Эксперт РА» [Электронный ресурс]: аналитические материалы - Официальный сайт компании «Эксперт РА», 2020.- Режим доступа: www.raexpert.ru 